\title{
Comunicação
}

[Communication $]$

\section{Método não invasivo para avaliação da movimentação embrionária de Caiman yacare (Daudin, 1802)}

[Non-invasive method for evaluation of embrionic moviment of Caiman yacare (Daudin, 1802)]

\author{
L.G. Gomes ${ }^{1}$, M.B. Stocco ${ }^{1}$, N.P. Sousa ${ }^{2}$, A.C. Martini ${ }^{1}$, T.O. Morgado ${ }^{3}$, \\ F.N. Flôres ${ }^{4}$, L.F.B. Moreira ${ }^{5}$, R.H.S. Ferraz ${ }^{5}$, R.L. Souza $a^{5}$ \\ ${ }^{1}$ Programa de pós-graduação - Universidade Federal de Mato Grosso - Cuiabá, MT \\ ${ }^{2}$ Programa de graduação - Universidade Federal de Mato Grosso - Cuiabá, MT \\ ${ }^{3}$ Médica veterinária - Universidade Federal de Mato Grosso - Cuiabá, MT \\ ${ }^{4}$ Universidade Federal de Roraima - Boa Vista, RR \\ ${ }^{5}$ Universidade Federal de Mato Grosso - Cuiabá, MT
}

O jacaré-do-pantanal, espécie Caiman yacare (Marques, 2007), é amplamente utilizado na produção comercial e uma importante fonte de renda; para sua criação, são praticados dois sistemas: o Farming, com os adultos mantidos para a reprodução e os jovens criados até o abate, e o Ranching, com os ovos ou jovens coletados na natureza, e criados até o abate. Para este, a identificação, o transporte e a incubação exigem cuidados específicos, que devem ser seguidos (Breyer, 1987).

Em cada postura, uma fêmea deposita entre 2540 ovos e com período de incubação de aproximadamente 70-80 dias. $\mathrm{O}$ sexo dos embriões é determinado pela temperatura no ninho; temperaturas inferiores a $30^{\circ} \mathrm{C}$ produzem filhotes fêmeas e superiores a $30^{\circ} \mathrm{C}$, machos (Marques, 2007). A temperatura também é um fator determinante para a frequência cardíaca (FC) e o movimento dos embriões, influenciando sobre a taxa metabólica e consequentemente sobre o seu desenvolvimento (Du et al., 2011).

Há diversas técnicas para avaliar a viabilidade dos ovos, sendo elas: ovoscopia, acustocardiograma, eletrocardiograma e remoção de uma seção da casca ou confecção de "janelas" com posterior iluminação do embrião para visualização dos movimentos (Haque et al., 1994). No entanto, essas são invasivas e robustas, exigindo equipamentos que impedem sua utilização a campo ou na prática comercial,

Recebido em 15 de janeiro de 2019

Aceito em 15 de abril de 2019

E-mail: liannaghisi@gmail.com além de possuírem elevado risco de introdução de infecção. Tais práticas dificultam o acompanhamento do desenvolvimento embrionário em sistemas de criação, bem como para a maioria dos estudos e projetos que envolvam espécies ameaçadas (Pollard et al., 2016).

Já a utilização do método não invasivo para monitoração de motilidade e FC está tornando-se popular, atravessando diversos campos interdisciplinares devido a sua capacidade de preservação dos embriões. O monitor digital Egg $B u d d y^{\circledR}$ (Avian Biotech) detecta movimentação por meio de luz infravermelha, a qual ultrapassa a casca do ovo, captando pulsação de sangue nos vasos ou movimentos embrionários. Esse dispositivo já foi usado com sucesso para monitorar a saúde de embriões em trabalhos de conservação de espécies (Angilletta et al., 2013), assim como em pesquisas envolvendo fisiologia de ovos e desenvolvimento de embriões (Lima $e t$ al., 2011; Pollard et al., 2016; Pollard et al., 2017).

A literatura existente de jacarés brasileiros fornece informações sobre seu desenvolvimento e conservação (Lima et al., 2011), contudo há pouca literatura em âmbito nacional. Dessa forma, o presente estudo objetivou avaliar a viabilidade da utilização de um monitor digital não invasivo para monitorar a FC e a motilidade durante o desenvolvimento embrionário em diferentes temperaturas de incubação, a fim de 
enriquecer a literatura a respeito do jacaré-dopantanal. O projeto foi submetido à Comissão de Ética no Uso de Animais (Ceua) da Universidade Federal de Mato Grosso (UFMT), sob número de protocolo 23108.321196/2017-53, e ao Sistema de Autorização e Informação em Biodiversidade (Sisbio), sob número de protocolo 61288-2, para coletas provenientes do Parque Zoológico da UFMT.

A coleta dos ovos seguiu o sistema Ranching, com identificação, transporte e incubação realizados de acordo com os cuidados exigidos e determinados para jacarés-do-pantanal (Breyer, 1987). Manualmente, os ovos foram coletados do ninho, receberam uma marcação (X) para garantir a manutenção de sua posição original e foram acondicionados lado a lado, no interior de caixas plásticas forradas com material orgânico retirado do ninho. As caixas foram fechadas e identificadas em relação à data e ao ninho de coleta. Por fim, os ovos foram transferidos para incubadoras apropriadas, com temperatura e umidade controladas e identificadas com o número do respectivo ninho.

Para a incubação, foi estabelecida umidade de $90 \%$, e, a fim de evitar dimorfismos sexuais nas taxas de crescimento, foi empregada a temperatura de $29^{\circ} \mathrm{C}$, que resulta em embriões fêmeas, durante um período de 45 dias, para todos os ovos. Após esse período, a temperatura de incubação do grupo I continuou $29^{\circ} \mathrm{C}(\mathrm{n}=14)$ e a do grupo II elevou-se a $33^{\circ} \mathrm{C}(\mathrm{n}=14)$, para avaliação do movimento embrionário em menor e maior temperatura, respectivamente. $\mathrm{O}$ grupo III foi composto por ovos submetidos à temperatura de incubação de $29^{\circ} \mathrm{C}$, porém combinou-se à indução da hiperatividade por meio da injeção de 4-aminopyridine (4aminopiridina, Sigma-Aldrich ${ }^{\circledR}$, Alemanha) $\left(29^{\circ} \mathrm{C}-4 \mathrm{AP}\right)(\mathrm{n}=15)$, com o objetivo de estimular a contração da musculatura esquelética.

Nos dias 46, 47, 48 e 49, foram injetados $250 \mu \mathrm{L}$ de tampão fosfato-salino (PBS) contendo $0,2 \mu \mathrm{g}$ de 4-aminopiridina (4-AP), conforme descrito por Heywood et al. (2005). Para a aplicação do fármaco, os ovos foram abertos e posteriormente selados com adesivo para impedir infecções. A FC e os movimentos embrionários foram aferidos com o auxílio do monitor digital não invasivo Egg Buddy ${ }^{\circledR}$ (Avian Biotech, Animal Genetics, Inglaterra), removendo-se unitariamente os ovos de seu recipiente de incubação e, assim, acomodando-os no aparelho durante dois minutos/embrião, nos dias 30, 35, 42, 49, 56 e 60 (Hammond et al., 2007).

Os embriões foram submetidos à eutanásia, no terço final de seu desenvolvimento, 60 dias de incubação, em estrita observação às determinações da Resolução CFMV No 1000, de 11 de março de 2012. Em seguida, avaliaram-se diferentes dados de cada embrião, como comprimento total do corpo, do nariz e dos membros e de seus elementos, além de se coletarem amostras biológicas; por fim, uma parte foi armazenada a $-80^{\circ} \mathrm{C}$ e a outra fixada em formaldeído $10 \%$, para análises futuras. As análises estatísticas foram realizadas por meio do software $\mathrm{R}^{\circledR}$, versão 3.2.0. Foi utilizada a análise de variância (ANOVA) para $o$ fator (temperatura) e a de medidas repetidas para a movimentação embrionária. As diferenças foram consideradas significativas quando $\mathrm{P}<0,05$.

Optou-se pela classe Reptilia, pois são excelentes modelos experimentais para esse tipo de estudo, em se tratando de animais ectotérmicos e ovíparos, para os quais a incubação não depende diretamente dos pais, assim como descrito por Pollard et al. (2017). Isso torna possível explorar a motilidade em diferentes temperaturas, o que se assemelha aos eventos naturais, diferentemente dos estudos realizados em aves, uma vez que essas possuem uma biologia distinta, com incubação realizada obrigatoriamente por um dos pais, bem como uma variedade de espécies que alteram o seu comportamento para manter a temperatura ideal no ninho (Conway e Martin, 2000).

Apesar de existirem diferentes métodos de avaliação para detecção da movimentação de ovos embrionados, fez-se uso do monitor digital Egg Buddy ${ }^{\circledR}$, pois, segundo Pollard et al. (2016), é um método confiável e não invasivo que elimina risco de infecção, além de ser uma ferramenta segura para espécies ovíparas ameaçadas, por não requerer eutanásia ao final do estudo. Outras vantagens são descritas pelos autores, como limitação dos impactos externos causados pela luz, durante a ovoscopia, sobre os estímulos embrionários e facilidade no transporte e uso a campo.

A avaliação da movimentação embrionária foi realizada nos dias 30,35, 42, 45, 49, 56 e 60 
(Fig. 1), o que proporcionou o acompanhamento dos embriões em diferentes fases de desenvolvimento. No dia 30, as médias \pm desviopadrão obtidos foram relativamente inferiores quando comparados com os outros dias avaliados: $24,57 \pm 41,06, \quad 22,78 \pm 46,13$ e $12,92 \pm 32,86$, para $33^{\circ} \mathrm{C}, 29^{\circ} \mathrm{C}$ e $29^{\circ} \mathrm{C}-4 \mathrm{AP}$, respectivamente. Isso ocorreu visto que parte dos ovos mensurados não apresentaram movimento no dia relacionado, devido ao método utilizado, que limita a verificação dos movimentos em fases iniciais do desenvolvimento (Pollard et al., 2016); apesar da dificuldade na obtenção dos dados neste dia, não há inviabilização das análises, uma vez que a movimentação só ocorre em fases posteriores a esta, a partir da existência de cavitação articular nos membros, como descrito por Pitsillides (2006). No jacaré-dopantanal, a formação da cavitação articular só ocorre após 30 dias de incubação (Lima et al., 2011).

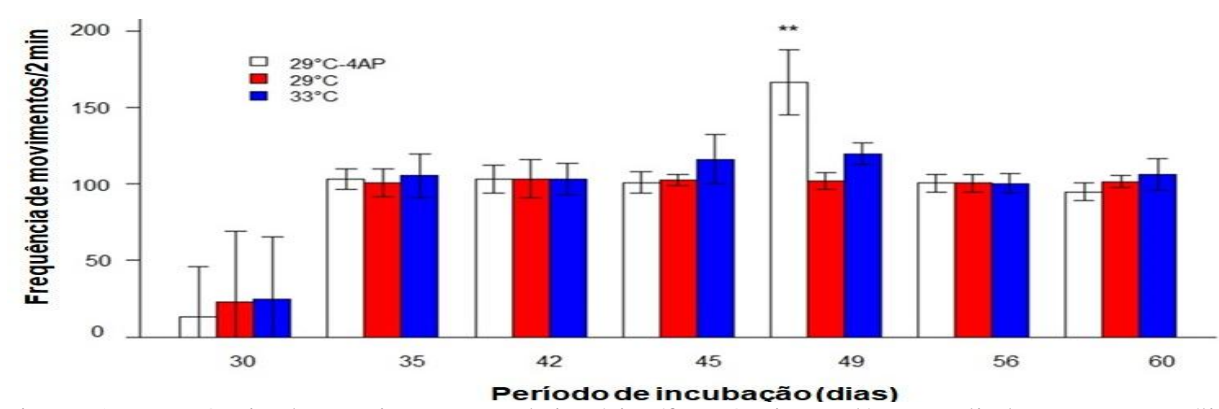

Figura 1. Frequência de movimentos embrionários/frequência cardíaca avaliadas com o auxílio do monitor digital Egg Buddy ${ }^{\circledR}$ (Avian Biotech, Animal Genetics, Inglaterra), por um período de dois minutos/embrião, realizadas nos dias 30, 35, 42, 45, 49, 56 e 60, para acompanhamento da incubação de jacaré-do-pantanal (Caiman yacare) $(* * \mathrm{P}<0,001)$.

Nos dias 35, 42, 56 e 60, os valores se mantiveram estáveis entre os grupos, e não se identificou diferença nos dados obtidos. Já nos dias 45 e 49 , na temperatura de $33^{\circ} \mathrm{C}$, observouse movimentação embrionária relativamente superior em comparação com o grupo de $29^{\circ} \mathrm{C}$; adicionalmente, a inclusão da $4-\mathrm{AP}\left(29^{\circ} \mathrm{C}-4 \mathrm{AP}\right)$ promoveu diferença estatística significativa $(\mathrm{P}<0,001)$ no dia 49 e evidenciou a influência da medicação sobre a movimentação embrionária. Em galinhas, o aumento da temperatura de incubação dos ovos e a inoculação 4-AP produziram aumento de motilidade embrionária, observada por meio de métodos invasivos e não invasivos (Hammond et al., 2007; Pollard et al., 2014), assim como observado neste estudo, com o uso do monitor digital não invasivo, sendo eficaz para a monitoração da motilidade e da FC e capaz de rastrear embriões de Caiman yacare viáveis e saudáveis. A partir do dia 60, há diminuição dos movimentos em comparação com a avaliação anterior (49 dias), pois esse evento ocorre devido ao crescimento dos embriões e à existência de limitação física, ovo, (Pollard et al., 2017), o que explica a diminuição dos movimentos no período final de incubação.

Dessa forma, é possível afirmar que a motilidade embrionária e a FC podem ser avaliadas, de maneira eficaz, em embriões de Caiman yacare a partir dos 30 dias de incubação pelo método digital não invasivo, Egg Buddy ${ }^{\circledR}$. Vale ressaltar que esse método também pode contribuir para estudos conservacionais de diferentes espécies ovíparas, principalmente das ameaçadas de extinção. Ademais, é um método que pode ser empregado em trabalhos de campo, devido a sua facilidade na verificação da motilidade dos ovos avaliados, além de ser instituído na prática comercial de criadouros de jacarés que utilizam o método Ranching de criação.

Palavras-chave: movimento embrionário, temperatura, jacaré-do-pantanal

\section{ABSTRACT}

This study aimed to evaluate the viability of using a non-invasive digital monitor to monitor heart rate (HR) and motility during the embryonic development of Pantanal alligator (Caiman yacare) using Egg Buddy ${ }^{\circledR}$, at different incubation temperatures. The collection of the eggs followed the Ranching system and egg 
identification, transportation, and incubation were performed with the required care; all eggs were incubated with $90 \%$ humidity at $29^{\circ} \mathrm{C}$ for the first 45 days. Thereafter, the incubation temperature was either maintained at $29^{\circ} \mathrm{C}$, increased to $33^{\circ} \mathrm{C}$ or maintained at $29^{\circ} \mathrm{C}$ and embryos simultaneously treated with 4 -aminopyridine on days 46, 47, 48, and $49\left(29^{\circ} \mathrm{C}-4 \mathrm{AP}\right)$. Embryo movement was measured with a digital non-invasive monitor on days 30, 35, 42, 49, 56, and 60, at which point embryos were sacrificed. In the statistical analysis no differences were observed between the groups for the temperature $\left(33^{\circ} \mathrm{C}\right.$ and $\left.29^{\circ} \mathrm{C}\right)$; for motility, a difference was observed at day 49 for the $29^{\circ} \mathrm{C}-4 \mathrm{AP}$ group. This revealed that the non-invasive evaluation method can be used to verify embryonic motility and HR effectively in Caiman yacare embryos.

Keywords: embryonic motility, temperature, pantanal alligator

\section{AGRADECIMENTOS}

Os autores agradecem à Fapemat - Fundação de Amparo à Pesquisa do Estado de Mato Grosso.

\section{REFERÊNCIAS}

ANGILLETTA Jr., M.J.; ZELIC, M.H.; ADRIAN, G.J. et al. Heat tolerance during embryonic development has not diverged among populations of a widespread species (Sceloporus undulatus). Conserv. Physiol., $\quad$ v.1, $\quad$ p.1-9, 2013. [<https://www.ncbi.nlm.nih.gov/pmc/articles/PMC480 6623/pdf/cot018.pdf $>$. Acesso em: 05, Jan, 2019.].

BREYER, F.R.S. Técnicas para a coleta, transporte e incubação artificial de ovos de Caiman crocodylus yacare (Daudin, 1802), (Crocodylia: alligatoridae). Corumbá: Embrapa, 1987. p.1-8. (Comunicado Técnico, n.8). [<https://www.embrapa.br/busca-depublicacoes/-/publicacao/787740/tecnicas-para-acoleta-transporte-e-incubacao-artificial-de-ovos-decaiman-crocodylus-yacare-daudin-1802-crocodyliaalligatoridae>. Acesso em: 05, Jan, 2019.].

CONWAY, C.J.; MARTIN, T.E. Effects of ambient temperature on avian incubation behavior. Behav. Ecol. Sociobiol., v.11, p.178-188, 2000. [<https://academic.oup.com/beheco/article/11/2/178/2 04702>. Acesso em: 05, Jan, 2019.].

DU, W.; YE, H.; ZHAO, B. et al. Patterns of interspecific variation in the heart rates of embryonic reptiles. Plos One, v.6, p.1-9, 2011. [<https://journals.plos.org/plosone/article?id=10.1371/ journal.pone.0029027>. Acesso em: 13, Dez, 2018.].

HAMMOND, C.L.; SIMBI, B.H.; STICKLAND, N.C. In ovo temperature manipulation influences embryonic motility and growth of limb tissues in the chick (Gallus gallus). J. Exp. Biol., v.210, p.2667-2675, 2007.

[<https://jeb.biologists.org/content/210/15/2667.long〉. Acesso em: 13, Dez, 2018.].

HAQUE, M.A.; WATANABE, W.; ONO, H. et al. Comparisons between invasive and noninvasive determinations of embryonic heart rate in chickens. Comp. Biochem. Physiol., v.108, p.221-227, 1994. [<https://www.sciencedirect.com/science/article/pii/03 00962994900884>. Acesso em: 06, Jan, 2019.].
HEYWOOD, J.L.; McENTEE, G.M.; STICKLAND, N.C. In ovo neuromuscular stimulation alters the skeletal muscle phenotype of the chick. J. Muscle Res. Cell Motil., v.26, p.49-56, 2005. [<https://link.springer.com/article/10.1007\%2Fs10974 -005-9007-8>. Acesso em: 06, Jan, 2019.].

LIMA, F.C.; VIEIRA, L.G.; SANTOS, A.L.Q. et al. Skeletogenesis of the pectoral girdle and forelimbs in embryos of Caiman yacare (Daudin, 1802) (Crocodylia, Alligatoridae). J. Morphol. Sci., v.28, p.4-10, $2011 . \quad$ [< https://www.researchgate.net/publication/289025730_ Skeletogenesis_of_the_pectoral_girdle_and_forelimbs _in_embryos_of_Caiman_yacare_Daudin_1802_Croc odylia_Alligatoridae>. Acesso em: 05, Jan, 2019.].

MARQUES, M.S. Estudo comportamental de Caiman yacare (Jacaré-do-Pantanal) in situ e ex situ. Rev. Cient. Faminas, v.3, p.11-20, 2007.

PITSILLIDES, A.A. Early effects of embryonic movement: 'a shot out of the dark'. J Anat., v.208, p.417-431, 2006. [<https://www.ncbi.nlm.nih.gov/pmc/articles/PMC210 0206/pdf/joa0208-0417.pdf >. Acesso em: 05, Jan, 2019.].

POLLARD, A.S.; MCGONNEL, I.M.; PITSILLIDES, A.A. Mechanoadaptation of developing limbs: shaking a leg. J. Anat., v.224, p.615-623, 2014. [<https://www.ncbi.nlm.nih.gov/pmc/articles/PMC402 5889/pdf/joa0224-0615.pdf $>$. Acesso em: 06, Jan, 2019.].

POLLARD, A.S.; CHARLTON, B.G.; HUTCHINSON, J.R. et al. Limb proportions show developmental plasticity in response to embryo movement. Sci. Rep., v.7, n.41926, 2017. [<https://www.nature.com/articles/srep41926>. Acesso em: 06, Jan, 2019.].

POLLARD, A.S.; PITSILLIDES, A.A.; PORTUGAL, S.J. Validating a noninvasive technique for monitoring embryo movement in ovo. Physiol. Biochem. Zool., v.89, p.331-339, 2016. [https://www.journals.uchicago.edu/doi/10.1086/6872 28>. Acesso em: 06, Jan, 2019.]. 